\title{
Taxane-Pocket Binding Agent
}

National Cancer Institute

\section{Source}

National Cancer Institute. Taxane-Pocket Binding Agent. NCI Thesaurus. Code C67437.

Any of a class of anti-mitotic compounds that bind to the taxane site of the beta-tubulin subunit, a region described as a binding pocket located within the middle domain and corresponding to an approximate residue sequence of 217-231. Specifically, these agents bind to a cysteine residue within the pocket, which is also the binding site for GTP. Agents binding at the taxane site promote the polymerization of dimers to form a very rigid and stable microtubule structure which is not readily disassembled. By interfering with microtubule dynamics these agents inhibit the normal turnover process essential during mitosis, thereby causing cell-cycle arrest and/or apoptosis. 